\title{
On the question of a new conflictological thinking in the framework of the integration science of politics
}

\author{
A. V. Solovyov ${ }^{1}$
}

${ }^{1}$ RANEPA, 82 Vernadsky Ave., Moscow 119571, Russian Federation

DOI: $10.18255 / 2412-6519-2020-2-142-151$

Research Article

Full text in Russian

The author presents his own vision of the actual problems facing political conflictology as a discipline included in the structure of political science. Attention is drawn to the actual problems facing the authors who develop the problems of political conflictology. They are caused by the fact that conflicts are a phenomenon of political reality, and political management of society includes both the process of conflict reproduction and the process of conflict resolution. Two views of the policy are given. According to one, politics is a program of action and the result of people's actions, while the other characterizes politics as a space of competition and contradictions. Both do not exclude the conflict from the political sphere, moreover, they are an integral part of any political process. Loss of manageability, transition to "manual management", unpopular decisions of the government lead to the absence of a full-fledged policy, to the growth of citizens' distrust of government institutions.

Keywords: political conflictology; public policy and management; conflict-productionand conflictresolution; social tension

INFORMATION ABOUT THE AUTHORS

Soloviev Anatoliy V.

E-mail: savhome@yandex.ru

Doctor of Sciences in Economics, Professor of the Department of labor and social policy

For citation: Solovyov A. V. On the question of a new conflictological thinking in the framework of the integration science of politics // Social'nye i gumanitarnye znanija. 2020. Vol. 6, No 2. P. 142-151. (in Russ.) 
политология

\title{
К вопросу о новом конфликтологическом мышлении в рамках интеграционной науки о политике
}

\author{
А. В. Соловьев ${ }^{1}$
}

1РАНХиГС, проспект Вернадского, 82, Москва, 119571, Российская Федерация

DOI: 10.18255/2412-6519-2020-2-142-151

УдК 323

Научная статья

Полный текст на русском языке

Автор излагает собственное видение актуальных проблем, стоящих перед политической конфликтологией как дисциплиной, входящей в структуру политической науки. Обращается внимание на актуальные проблемы, стоящие перед авторами, разрабатывающими проблематику политической конфликтологии. Эти проблемы обусловлены тем, что конфликты - явление политической реальности, и политическое управление обществом включает как процесс конфликтовоспроизводства, так и процесс конфликторазрешения. Приводятся два представления о политике. Согласно одному, политика - программа действия и результат действия людей, другое характеризует политику как пространство конкурентной борьбы и противоречий. И то, и другое не исключают конфликты из политической сферы, более того, они являются неотъемлемой частью любого политического процесса. Потеря управляемости, переход к «ручному управлению», непопулярные решения власти приводят к отсутствию полноценной политики, к росту недоверия граждан к институтам власти, провоцируют социальное напряжение и в политической, и в экономической, и в социальной сферах, обостряются отношение населения с властью и в трудовой сфере. Поскольку в политике осуществляется не только борьба, но и диалог, она является пространством не только конфликтов, но и компромиссов. Потребности политического компромисса обусловили предложение Президента Российской Федерации вынести вопрос об изменениях в Конституции и доверии/недоверии президенту на всенародное обсуждение.

Ключевые слова: политическая конфликтология; государственная политика и управление; конфликтопроизводство и конфликторазрешение; социальная напряженность

ИНФОРМАЦИЯ ОБ АВТОРАХ

Соловьев Анатолий | E-mail: savhome@yandex.ru

Владимирович Доктор экономических наук, профессор кафедры труда и социальной политики

Для цитирования: Соловьев А. В. К вопросу о новом конфликтологическом мышлении в рамках интеграционной науки о политике // Социальные и гуманитарные знания. 2020. Том 6, № 2. С. $142-151$.

(C) Соловьев А. В., 2020

Статья открытого доступа под лицензией CC BY-NC-ND (http://creativecommons.org/licenses/by-nc-nd/4.0/) 
Предмет дискуссии - политическая наука в поисках нового мышления - носит характер провокации. В данном случае под провокацией понимается побуждение к поиску путей развития политической науки. Вспомним, что ребёнок приходит в наш мир и начинает мыслить, не имея никакой мыслительной базы. Поэтому, когда на повестку дня вынесено обсуждение проблемы нового мышления представителей политической науки, то, скорее, ожидается разговор не только о поисках новых направлений в осмыслении актуальных вопросов бытия, но и о состоянии базы политологического знания. Именно такой вывод, на мой взгляд, можно сделать, прослушав доклады профессоров Т. А. Алексеевой и Л. В. Сморгунова. От оценки основных докладов первых Субботних политологических чтений в Президентской академии перейду к изложению заявленной мной темы.

В структуру политической науки входит такая научная дисциплина, как политическая конфликтология. Естественно, что при обсуждении такой темы, как «Политическая наука в поисках нового мышления», целесообразно обратить внимание на некоторые аспекты актуальных проблем, стоящих перед авторами, разрабатывающими проблематику политической конфликтологии. Обусловлено это тем, что социальный конфликт является одним из объектов политической реальности, а проблематика политического управления обществом включает в себя и проблему конфликтовоспроизводства, и проблему конфликторазрешения [1].

Вслед за некоторыми отечественными конфликтологами [2] можно утверждать, что одним из направлений политической конфликтологии является исследование внутриполитических конфликтов. Однако, заявляя это, необходимо обратить внимание на некоторые противоречия, существующие на данном этапе развития политической науки.

Так, например, понятие «политика», ставшее междисциплинарным, т. е. используемым представителями других общественных наук, приобрело однобокое понимание. Это означает, что практически забыт дуализм сущности этого понятия, раскрытый Раймоном Ароном [3]. Большинство отечественных авторов раскрывает понятие «политика» в значении английского термина «policy» - концепция, мероприятия, программа действий, а то и сами действия группы людей, правительства по отношению к какой-либо проблеме или совокупности проблем, существующих в обществе.

Во втором значении слово «политика» (англ. politics) относится к той области общественной жизни, где конкурируют или противоборствуют различные политические направления, мировоззрения, где конкурируют или противоборствуют различные политические направления в значении policy. Таким образом, в значении politics политика - это область (пространство), внутри которой борются или ведут социальный диалог различные общественные слои и группы, имеющие собственную policy, т. е. свои цели, свои интересы, а то и свое мировоззрение.

Оба значения (policy и politics) взаимосвязаны и обладают потенциалом возникновения социальных конфликтов.

С точки зрения конфликтологии, политика как концепция, мероприятия, программа действий, разработанные и реализуемые, например, ведущей политической партией или правительством, обладает потенциалом возникновения социальных конфликтов postfactum. В качестве отечественных примеров можно напомнить 
о «зурабовской» монетизации льгот [4], а также привести ситуацию воспроизводства социальной напряженности в обществе в результате принятия решения о повышении в России пенсионного возраста в тот период времени, когда ряд зарубежных стран принял решение противоположного характера, то есть о снижении ранее повышенного пенсионного возраста [5].

Существует точка зрения, согласно которой задачей политического анализа становится выявление напряженности вообще [6]. Но что скрывается за конфликтологическим понятием «повышение социальной напряженности»? Применительно к социально-трудовой сфере ответ таков: на практике со стороны российских трудящихся не только возросло недоверие к власти, но и поменялось отношение к труду, не говоря об отношении к инновациям, без которых не может произойти экономического роста. В целом можно утверждать, что повышение социальной напряженности за счет непопулярного в обществе решения со стороны власти увеличило количество трудящихся, вовлеченных в скрытое сопротивление на рабочих местах [7; 8] таким задачам, как рост производительности труда и внедрение инноваций.

В данном контексте уместно напомнить об оценке внешней среды со стороны Комитета по свободе объединения Международной организации труда (далее - Комитет). Она была сформулирована в ходе освещения права трудящихся на забастовку. Итак, Комитет отмечает, что «политика правительства нередко вызывает прямые последствия для трудящихся и предпринимателей, например, в случае введения мер по замораживанию цен и заработной платы» [9].

В современной России объективно существует конфликт между риторикой необходимости социально-экономического развития страны и отсутствием надлежащих управленческих решений на государственном уровне для создания условий для такого развития. В результате происходит демотивация трудящихся к труду результативному и качественному [10]. На этот конфликт можно было бы не обращать внимания, если бы не следующее обстоятельство. Согласно точке зрения Дэвида Трумэна, любая активность (и активность трудящихся), связанная с управлением, становится политической [11].

Таким образом, можно утверждать, что в рамках конфликтологической концепции представителям политической науки необходимо больше внимания уделить проблематике конфликтопроизводства со стороны институтов и органов современного государства1. С одной стороны, это согласуется с выводом Йозефа Шмида о том, что современное государство выступает в двух ипостасях - как «конфликтопроизводящее государство» и как «конфликторазрешающее государство» [1]. При этом, с другой стороны, в современных условиях политика как нерыночное производство решений относительно публичных благ [13] должна формироваться и осуществляться так, чтобы минимизировать конфликты в обществе. Последнее означает, что политика не должна приводить к грубому попранию конституционной нормы об обеспечении достойной жизни и свободном развитии человека (ч. 1 ст. 7 Конституции РФ).

\footnotetext{
${ }^{1}$ О свойствах современного государства см. [12].
} 
Проблемное поле конфликтопроизводства современным государством включает в себя вопросы идентификации интересов управляемых с интересами субъекта, принимающего политические решения (1), общности интересов властвующих и подвластных (2), обратной связи между управляющими и управляемыми (3), политической ориентации (4), политического выбора (5), политической ответственности (6), замещения государственного управления управлением государственных чиновников (7).

Отдельно отметим точку зрения Джеймса Фишкина: «Убеждение - самая приемлемая форма политической власти. Любая другая власть понижает автономию и самоопределение индивидов»[12]. К этому можно добавить, что эта приемлемая форма политической власти работает и на адаптацию подвластных, и на предупреждение социального конфликта. Следовательно, в процесс принятия управленческих решений в масштабе государства должна входить такая компонента, как конструктивное убеждение подвластных в целесообразности определенного решения. Но если принятое решение по той или иной причине не будет адекватно воспринято подвластными, то в этом случае необходимо оценивать состояние конфликтного потенциала новой реальности. Так, например, произошло в 2008 году, когда Правительством РФ была утверждена Концепция долгосрочного социально-экономического развития Российской Федерации на период 2008-2020 гг. Ожидаемой мобилизации российских трудящихся на повышение производительности труда в показателях, предусмотренной этой Концепцией, не произошло. Этого и не могло произойти, так как разработчики Концепции и Правительство РФ не предусмотрели ни показателей повышения уровня жизни трудящихся, ни мер, направленных на решение такой задачи.

Можно утверждать, что указанная Концепция-2020 по своему содержанию отвечала подходу, согласно которому «социальная политика должна заниматься не только и не столько опекой, сколько предъявлять высокие требования к работнику» [14].

Далее обратим внимание на второе определение политики и её конфликтологический потенциал. Итак, когда политика понимается как область (пространство), внутри которой борются или ведут социальный диалог различные общественные слои и группы, то между взаимодействующими общественными слоями и группами могут возникать как конфликты, так и компромиссы.

На современном этапе общественной жизни, когда осуществляется идеология социального партнёрства не только в социально-трудовой сфере, но и во взаимодействии институтов и органов гражданского общества и государства, теоретически нет оснований для возникновения социальных конфликтов. Общественные организации в своём большинстве, как и в один из периодов существования СССР, действуют по отношению к власти по принципу «одобрямс». Очевидно, не надо пояснять, что таким образом они одобряют внутреннюю политику государства. И про- 
исходит это на фоне потери управляемости системой государственного строительства, в которой имеет место беспримерный разгул таких феноменов, как коррупция1, клиентелизм [16], непотизм.

Поясним, что потеря управляемости привела к тому, что в лексиконе политологов появилось выражение «ручное управление» [17]. Потеря управляемости в масштабах страны имеет негативные последствия, среди которых можно выделить как отсутствие полноценной политики [18], так и рост недоверия граждан к институтам власти. Последний фактор приобрел для представителей власти особое значение, поскольку в ходе обсуждения предложенных Президентом РФ изменений в Конституцию на повестку дня был вынесен вопрос о характере плебисцита - о доверии 2 или недоверии непосредственно Президенту РФ.

Далее целесообразно обратить внимание на такой аспект «нового мышления», как осознание природы конфликта интересов, который проявляется в системе государственного управления и объективно приводит к дисфункциональным (деструктивным) последствиям, поскольку имеет коррупционную основу. Обусловлено это несколькими причинами. Во-первых, в литературе по конфликтологии, включая справочную, понятие «конфликт интересов» раскрывается, неоднозначно, своеобразно. Так, например, в произведении «Конфликтология: терминологический словарь» под конфликтом интересов понимается «противоборство групп чиновников государственной и муниципальной службы за получение теневых выгод от использования своих должностных обязанностей» [19].

Во-вторых, представители юридической науки имеют собственное понимание сущности конфликта интересов. Так, в одном случае это понятие раскрывается как «ситуация, при которой заинтересованность государственного или муниципального служащего в получении личной выгоды ведет к ненадлежащему исполнению служебных обязанностей и причиняет ущерб правам и интересам граждан, групп и организаций» [Там же]. В другом случае конфликт интересов характеризуется как одна из стадий развития юридического конфликта, а точнее, предконфликтная ситуация [20].

B-третьих, авторы отечественного словаря конфликтолога раскрывают понятие «конфликт интересов» без учёта того факта, что это понятие может использоваться как в ситуациях противоборства субъектов социально-трудовых отношений, обладающих конкурирующими экономическими интересами, так и в ситуациях проявления коррупции во всех общественных отношениях [21].

B-четвертых, в учебной литературе по проблематике государственной политики и управления порой можно встретить точку зрения о причине возникновения конфликта интересов, которую разделить трудно. Так, например, полагается, что конфликты в системе государственного управления, имеющие коррупционную основу, вызваны противоречием «между абстрактными общезначимыми нормами и потребностями граждан» [1].

\footnotetext{
${ }^{1}$ Е. В. Охотский пишет о коррумпированности государства: «Коррумпированное государство - тематика крайне актуальна для российского государства. <... > Основной сущностной характеристикой такого государства является элитная коррупция, связанная с корыстными злоупотреблениями в большой политике, государственном и муниципальном управлении» [15].

2В. П. Макаренко отмечает, что в современной политической теории доверие почти не изучается [12].
} 
Нельзя не обратить внимания и на подход представителей юридической науки на проблему противодействия коррупции, в которой конфликт интересов занимает особое место. Так, полагается, что урегулирование конфликта интересов это основной способ предупреждения коррупции в системе государственного управления. При этом выражается мнение, согласно которому этот институт существенно эволюционировал и из фактически не работающего до 2011 года превратился в мощный инструмент реализации антикоррупционной политики [20].

Остановимся на термине «институт урегулирования конфликта интересов». Поскольку конфликт интересов возникает и протекает в среде институциональных отношений (трудовых, служебных и пр.), то под термином «институт урегулирования конфликта интересов» следует понимать группу норм права, содержащихся в действующем законодательстве и предусматривающих порядок урегулирования конфликта интересов. Но содержит ли российское законодательство группу норм права, предусматривающих порядок урегулирования конфликта интересов?

Порядок урегулирования предусмотрен ст. 11 Федерального закона от 25 декабря 2008 г. № 273-Ф3 «0 противодействии коррупции» (с изменениями на 16 декабря 2019 года1). В соответствии с ч. 4 ст. 11 указанного законодательного акта «Предотвращение или урегулирование конфликта интересов может состоять в изменении должностного или служебного положения лица, указанного в части 1 статьи 10 настоящего Федерального закона, являющегося стороной конфликта интересов, вплоть до его отстранения от исполнения должностных (служебных) обязанностей в установленном порядке и (или) в отказе его от выгоды, явившейся причиной возникновения конфликта интересов».

По смыслу приведенной нормы весь порядок урегулирования конфликта интересов, имеющего коррупционную основу, сводится к изменению должностного или служебного положения лица, вовлеченного в коррупционное деяние или совершившего его.

С точки зрения осуществления прагматической функции политической конфликтологии необходимо понять, что: 1) по своей природе конфликт интересов, имеющий коррупционную основу, является морально-правовым конфликтом [22]; 2) для урегулирования конфликта интересов в него должно вмешиваться такое третье лицо, которое по праву способно определить вину государственного или муниципального служащего и привлечь его к соответствующей юридической ответственности; 3) проведение процедуры медиации (посредничества) с целью разрешения конфликта интересов нецелесообразно [Там же].

Обратим внимание на дуализм природы конфликта интересов, обладающего коррупционной основой, поскольку это имеет непосредственное отношение к вопросу, какая работа (или обхождение, по Ф. Глазлу [23]) с этим конфликтом должна быть выбрана, если в теории конфликтологии существует множество понятий, описывающих все возможные способы воздействия на конфликт. Так, например, при возникновении морального конфликта может идти речь о его преодолении [24]. Применительно к рассматриваемому нами морально-правовому конфликту следует использовать выражение «урегулирование конфликта». Обусловлено

\footnotetext{
${ }^{1}$ Федеральный закон Российской Федерации от 25.12.2008 г. № 273-Ф3 «О противодействии коррупции». URL: http://docs.cntd.ru/document/902135263
} 
это тем, что вмешательство в этот конфликт должно осуществляться третьим лицом, обладающим правомочием на установление виновного или невиновного поведения лица, выступающего в качестве непосредственного участника конфликта с коррупционной основой. Кроме того, это третье лицо должно обладать правомочием на привлечение лица, реально совершившего коррупционное деяние, к соответствующему виду юридической ответственности. А моральная составляющая анализируемого нами конфликта на практике может привести к тому, что лицо, совершившее коррупционное деяние, получит нравственное осуждение со стороны представителей общественности.

В данном контексте отметим, что некоторые представители отечественной политической науки порой делают необоснованные выводы по поводу урегулирования конфликта интересов, имеющего коррупционную основу. Так, например, при правильном понимании наличия в исследуемом конфликте такой составляющей, как моральная, полагается, что внедрение в систему государственной и муниципальной службы кодексов этики будет способствовать более успешному урегулированию таких конфликтов [25]. В данной связи следует заметить, что кодексы этики содержат рекомендации по должному поведению государственных и муниципальных служащих, то есть эти кодексы выступают дополнением к правовой культуре того или иного служащего. Но в современной России состояние правовой культуры в обществе находится на низком уровне, что усугубляется традиционным правовым нигилизмом [26].

Перейдём к следующей функции политической конфликтологии. В рамках инструментальной функции политической конфликтологии актуальной проблемой является методология предупреждения конфликта интересов, имеющего коррупционную основу. И здесь можно предложить следующие направления: 1) определение мер, направленных на изменение положения в части разрушения векторов социализации россиян, приведшей к криминализации психологии личности; 2) определение мер, направленных на установление реальных и эффективных барьеров на распространение «вируса» непотизма и клиентелизма.

Одним из объектов профилактического воздействия на личность в деле предупреждения конфликта интересов в системе государственной и муниципальной службы является правосознание, то есть система взглядов, оценок, представлений личности о сущности и характере правового администрирования относительно должного и юридически значимого поведения, правомерности или неправомерности того или иного поступка, имеющего в своей потенции определенные социальные последствия.

Всё сказанное очерчивает круг вопросов, которые, на наш взгляд, укладываются в проблемное поле политологии как интегративной науки, находящейся в поисках нового мышления.

\section{Ссылки / References}

1. Альгин А. П. Конфликты и государственное управление // Государственная политика и управление. Учебник. В 2 ч. Часть I. Концепции и проблемы государственной политики и управления / Под ред. Л. В. Сморгунова. М.: Российская политическая энциклопедия (РОССПЭН), 2006. С. 309-328. 
2. Большаков А. Г., Мансуров Т. 3. Политическая конфликтология. Конспект лекций. Казань, 2014. URL:

http://dspace.kpfu.ru/xmlui/bitstream/handle/net/22006/16_226_A5kl-000662.pdf (дата обращения: 15.02.2020)

3. Арон Р. Демократия и тоталитаризм. Пер. с франц. М.: Текст, 1993. 301 с.

4. Лужков Ю. М. Социальная нищета богатеющей страны // Бухгалтерский учёт в бюджетных и некоммерческих организациях. 2005. № 13 (133). С. 35-41.

5. Делягин М. Вслед за Францией и Польшей пенсионный возраст снижает Италия. Как так? Подробнее на «БИЗНЕС Online». URL: https://www.businessgazeta.ru/article/410254 (дата обращения: 15.02.2020)

6. Глухова А. В. Введение // Политическая конфликтология перед новыми вызовами / Под ред. А. В. Глуховой. Воронеж: Воронежский государственный университет, 2001. С. 7-10.

7. Соловьев А. В. Коллективные трудовые конфликты: сущность, формы и способы преодоления в современной России: автореф. дис. ... д-ра экон. наук. М., 2010. 51 с.

8. Соловьев А. В. Преодоление трудовых конфликтов коллективного характера: Монография. Ч. 1. Конфликтный потенциал социально-трудовой сферы. М.: РАПС, 2008. 226 c.

9. Свобода объединения. Сборник решений, принятых Комитетом по свободе объединения Административного совета МОТ, и выработанных им принципов. Женева, Международное бюро труда, 1997. 238 с.

10. Соловьев А. В. Факторы демотивации труда как объект управления человеческими ресурсами // Социально-экономические проблемы развития трудовых отношений в инновационной России: материалы Международной научно-практической конференции. Омск: Изд-во ОмГТУ, 2014. С. 225-235.

11. Сморгунова В. Ю. Феномен политического знания: Монография. СПб.: Образование, 1996. 432 c.

12. Макаренко В. П. Политическая концептология: обзор повестки дня. М.: Праксис, 2005. 368 c.

13. Сморгунов Л. В. Теория рационального выбора и сравнительная политология // Рациональный выбор политике и управлении / Под ред. Л. В. Сморгунова. СПб.: Издательство С.-Петербургского университета, 1998. 240 с.

14. Морозова Г. В. Социальная политика в целях перехода к рыночной экономике // Введение в политологию (учебное пособие). Казань: Издательство Казанского университета, 1992. С. 133-140.

15. Охотский Е. В. Управленческие патологии государства: неопределенности, дисфункции, социальные риски // Среднерусский вестник общественных наук. 2016. № 2. C. 57-70. 
16. Гаман-Голутвина О.В.Проблемы повышения эффективности государственного управления в Российской Федерации // Теория и практика государственного и муниципального управления / Под ред. В. С. Комаровского; Российская ассоциация политической науки (РАПН). Смоленск: Смоленская городская типография, 2010. C. $40-61$.

17. Комаровский В. С. Политика развития и трансформации модели государственного управления в России // Теория и практика государственного и муниципального управления / Под ред. В. С. Комаровского; Российская ассоциация политической науки (РАПН). Смоленск: Смоленская городская типография, 2010. С. 22-39.

18. Глухова А. В. Политическая конфликтология в поисках новой парадигмы // Политическая конфликтология перед новыми вызовами / Под ред. А. В. Глуховой. Воронеж: Воронежский государственный университет, 2001. С. 19-34.

19. Дмитриев А. В. Конфликтология: терминологический словарь. 2-е изд., испр. и доп. СПб.: СПбГУП, 2013. 80 с.

20. Цирин А. М., Севальнев В. В., Черепанова Е. В. Конфликт интересов: право и этика // Журнал зарубежного законодательства и сравнительного правоведения. 2018. № 3. (70). C. 49-63.

21. Анцупов А. Я., Шипилов А. И. Словарь конфликтолога. 4-е изд., испр. и доп. М.: Проспект, 2020. 536 с.

22. Соловьев А. В. Конфликт корыстных интересов на государственной и муниципальной службе: природа и способы преодоления: учебное пособие. 2-е изд., перераб. и доп. М.: Проспект, 2019. 256 с.

23. Глазл Ф. Конфликтменеджмент. Настольная книга руководителя и консультанта / Пер. с нем. Калуга: Духовное познание, 2002. 516 с.

24. Шепель В. М. Управленческая этика. М.: Экономика, 1989. 284 с.

25. Ирхин Ю. В. Этическое измерение модернизации деятельности государственных служащих (сравнительный анализ) // Модернизация и политическое развитие России. Сборник научных статей / Отв. ред.-сост. А. С. Фалина. М.: Проспект, 2012. С. 140-148.

26. Рахманин В. С. Факторы политической конфликтогенности в современном мире // Политическая конфликтология перед новыми вызовами / Под ред. А. В. Глуховой. Воронеж: Воронежский государственный университет, 2001. С. 65-87. 